\title{
Angioedema associated with the use of angiotensin-converting enzyme inhibitor
}

\author{
Amir M. Nia MD, Fikret Er MD
}

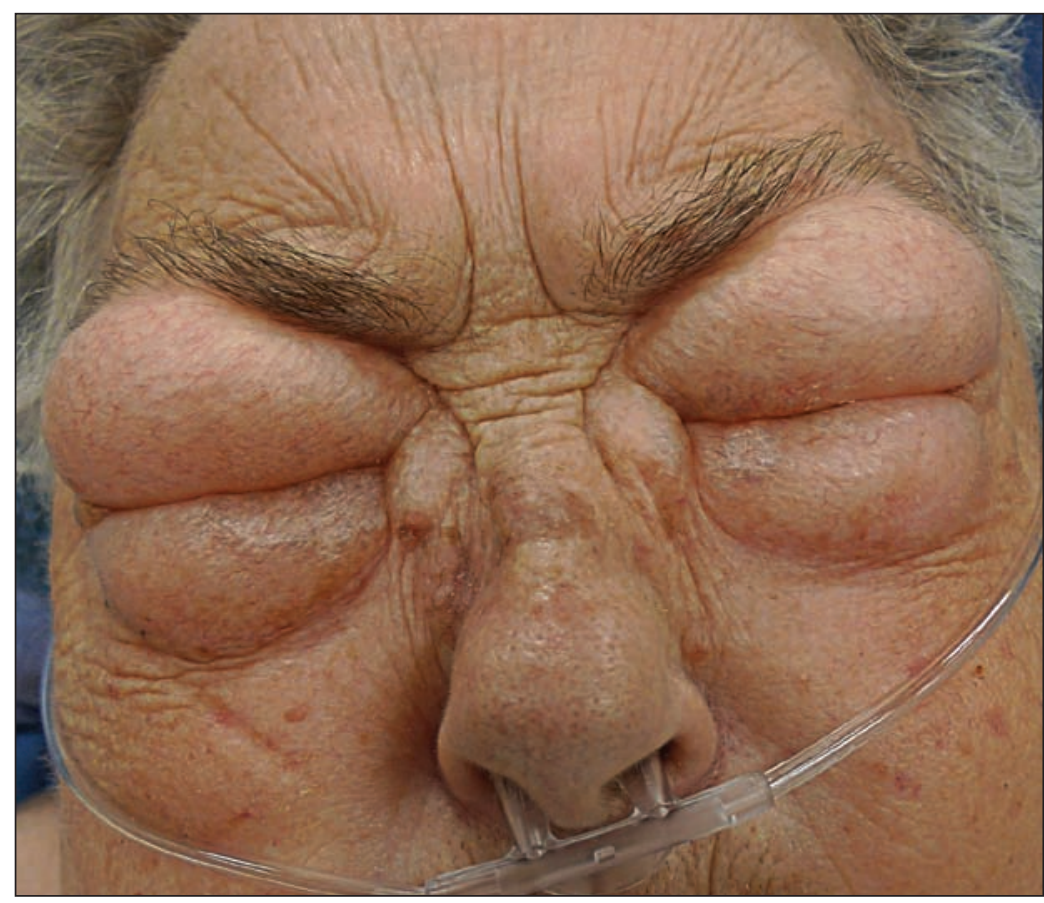

Figure 1: Several days after starting perindopril, a 71-year-old woman experienced shortness of breath and periorbital edema. She was also taking acetylsalicylic acid and bisoprolol.

Competing interests: None declared.

This article has been peer reviewed.

Affiliation: From the Department of Internal Medicine III, University of Cologne, Cologne,

Germany

Correspondence to:

Fikret Er,

fikret.er@uk-koeln.de

CMAJ 2013. DOI: 10.1503 /cmaj.111387

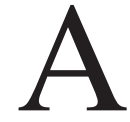

71-year-old woman presented with a sudden onset of shortness of breath and difficulty speaking. She was a former smoker and had no known allergies. During assessment, she experienced periorbital swelling without pruritus (Figure 1). She was immediately given antihistamine and cortisone treatment, and the swelling slowly resolved and her speech improved. On further enquiry, we found that she had been taking acetylsalicylic acid (ASA) and bisoprolol for hypertension and coronary artery disease for about 10 years, but she had started coughing after perindopril had been added to her medication several days earlier. We believed that perindopril alone or in combination with ASA was the most likely cause of the angioedema, and we changed her medication to amlodipine and clopidogrel. ${ }^{1}$ During three months of follow-up, neither angioedema nor cough recurred, and the laboratory results were not indicative of hereditary angioedema.

Adverse reactions after short- and long-term intake of angiotensin-converting enzyme (ACE) inhibitors alone or in combination with ASA are common..$^{1-3}$ Of those who use ACE inhibitors, angioedema occurs in about $0.5 \%$ of white people and up to $5 \%$ of black people. ${ }^{1}$ About onequarter of episodes occur during the first month of therapy. ${ }^{1}$ There are no known modifiable risk factors, but the risk appears to be higher for women than men and those with $\mathrm{C} 1$ esterase inhibitor deficiency, as well as for people of black and Asian descent. ${ }^{1,4} \mathrm{~A}$ history of asthma or urticaria may also be associated with increased risk, especially in combination with ASA use. ${ }^{1}$

After acute treatment of angioedema associated with the use of ACE inhibitors, experts recommend immediate discontinuation of the drug and strict lifetime avoidance of this class of medication. ${ }^{1-3}$ Although switching to an angiotensinreceptor blocker may improve ACE inhibitorassociated coughing, ${ }^{1-3}$ the high cross-reactivity (up to 17\%) between ACE inhibitors and angiotensin-receptor blockers may put those with previous episodes of ACE inhibitor-mediated angioedema at increased risk of further occurrences. ${ }^{2,3}$ Clinicians should avoid both classes of drugs for patients susceptible to ACE inhibitor-mediated angioedema to prevent potentially life-threatening complications., ${ }^{2,3}$

\section{References}

1. Vasekar M, Craig TJ. ACE inhibitor-induced angioedema. Curr Allergy Asthma Rep 2012;12:72-8.

2. Beavers CJ, Dunn SP, Macaulay TE. The role of angiotensin receptor blockers in patients with angiotensin-converting enzyme inhibitor-induced angioedema. Ann Pharmacother 2011:45:520-4.

3. Kanani A, Schellenberg R, Warrington R. Urticaria and angioedema. Allergy Asthma Clin Immunol 2011;7(Suppl 1):S9.

4. Hoover T, Lippmann M, Grouzmann E, et al. Angiotensin converting enzyme inhibitor induced angio-oedema: a review of the pathophysiology and risk factors. Clin Exp Allergy 2010;40:50-61. 